УДК 622.276

\title{
ОПТИМИЗАЦИЯ ПАРАМЕТРОВ НЕОРГАНИЧЕСКОГО АГЕНТА УПРАВЛЕНИЯ ПРОФИЛЕМ НА ОСНОВЕ СИЛИКАТА НАТРИЯ ДЛЯ ЭФФЕКТИВНОГО ВЫТЕСНЕНИЯ НЕФТИ ИЗ КОЛЛЕКТОРОВ С ВЫСОКОЙ МИНЕРАЛИЗАЦИЕЙ
}

\author{
Нажису', \\ Narisu33@126.com
}

Ерофеев Владимир Иванович',

erofeevvi@mail.ru

Лу Сянго ${ }^{2}$,

877459272@qq.com

Тянь Чжунъюань²,

jinjigema@126.com

\author{
Чжан Лидонг ${ }^{3}$, \\ 1052287742@qq.com \\ ' Национальный исследовательский Томский политехнический университет, \\ Россия, 634050, г. Томск, пр. Ленина, 30. \\ 2 Институт нефтегазового дела Северо-Восточного нефтяного университета, \\ Китай, 163000, г. Дацин, ул. Развития, 199. \\ ${ }^{3}$ Научно-исследовательский инженерно-технологический институт нефтяного месторождения Туха, \\ Китай, 838202, г. Шаньшань, ул. Освобождения, 67.
}

Актуальность. В настоящее время нефтяное месторождение Туха является месторождением со средней, низкой проницаемостью и с высокоминерализованной пластовой водой. Обводненность основного продуктивного пласта на участке «Ү» месторождения Туха составляет более 93 \%, поэтому необходимо применять эффективные технологии для повышения коэффициента извлечения нефти. Существующие полимеры, в том числе и солеустойчивые, не могут хорошо растворяться и распределяться в пластовой воде, обладают слабой способностью удерживания в пласте, управления потоком, поэтому трудно быстро достичь хорошего экономического эффекта от их внедрения. В связи с этим актуальной задачей является разработка метода управления профилем для эффективного вытеснения нефти из коллекторов с высокой минерализацией.

Цель: исследование эффективности вытеснения нефти и оптимизация параметров неорганического агента управления профилем на основе силиката натрия для повышения нефтеотдачи пластов.

Методы. Определение вязкости исследуемых образцов проводили на вискозиметре Брукфилда DV-II, эксперименты исследования влияния размера оторочек главного агента, количества циклов альтернативного заводнения, скорости закачки главного агента и закачки поверхностно-активного вещества на эффективность вытеснения нефти были проведены на фильтрационной установке.

Результаты. Для повышения нефтеотдачи пластов на месторождении Туха на основе геологических характеристик пласта и флюидных свойств участка «Ү» были проведены исследования по оптимизации параметров и увеличению эффективности вытеснения нефти неорганическим агентом на основе силиката натрия для управления профилями. Результаты показали, когда размер оторочек основного агента изменяется от 0,06 до 0,08 $V_{\text {зач }} / V_{\text {пор }}$ и количество циклов альтернативного заводнения составляет 5-6, степень использования слоев со средней и низкой проницаемостью более высокая, обводненность значительно уменьшается и коэффициент извлечения нефти значительно увеличивается. По сравнению с одиночным силикатным заводнением сочетание силиката натрия и поверхностного активного вещества может повысить объем охвата и коэффициент извлечения нефти.

\section{Ключевые слова:}

Коллектор с высокой минерализацией, силикат натрия, оптимизация, коэффициент увеличения нефтеотдачи, альтернативное заводнение.

\section{Введение}

В связи с длительной эксплуатацией нефтяных месторождений и их переходом в среднюю и позднюю стадию разработки для их более эффективной эксплуатации необходимы новые технологии для разработки глубокозалегающих месторождений с высокой минерализацией пластовых вод и высокой вязкостью нефти [1-4]. В настоящее время в связи с низкой солеустойчивостью полимеров большинство используемых полимеров и полимерных гелей подходят только для коллекторов, у которых степень минерализации воды ниже $8 \cdot 10^{4} \mathrm{мг} /$ л [5-8]. Создание и разработка солеустойчивых композиций для управления профилями имеет большое значение для уменьшения степени обводненности и увеличения нефтеотдачи в данном типе коллектора. В связи с низкой себестоимостью, высокой степенью блокировки, хорошей со- 
леустойчивостью и длительным периодом действия осадкообразующий неорганический агент управления профилями на основе силиката натрия постепенно стал наиболее подходящей композицией управления профилями для высокотемпературных и высоко минерализованных коллекторов [9-14]. Осадкообразующая композиция получается на основе силиката натрия через альтернативное заводнение основного агента, пластовой воды и разделительной жидкости в пласт для управления профилями. Между основным агентом (силикатом натрия) и катионами высоко минерализованной пластовой воды протекают химический реакции с образованием неорганического геля и осадка, которые осаждаются в поровом канале пласта, в результате чего уменьшается поперечное сечение пор, увеличивается фильтрационное сопротивление и последующий поток жидкости направляется в слой со средней и низкой проницаемостью, за счет этого увеличиваются коэффициент охвата пласта и нефтеотдача пласта [15-19]. Нефтяное месторождение Туха является месторождением со средней и низкой проницаемостью пластов и с высокоминерализованной пластовой водой. В настоящее время обводненность основного продуктивного пласта на участке «Y» месторождения Туха составляет более $93 \%$, а степень извлечения нефти менее $20 \%$. Общая минерализация пластовой воды изменяется от 115,5 до 191,8 г/л и концентрации $\mathrm{Ca}^{2+}$ и $\mathrm{Mg}^{2+}$ превышают 7 г/л. Существующие полимеры и солеустойчивые полимеры не могут хорошо раствориться и равномерно распределиться в пластовой воде, обладают слабой способностью удерживания в пласте и управления потоком, поэтому очень трудно получить хороший экономический эффект. В данной работе на основе геологических характеристик пласта и флюидных свойств участка «Ү» месторождения Туха была исследована эффективность вытеснения нефти и определены оптимальные параметры осадкообразующего неорганического агента на основе силиката натрия для управления профилями.

\section{Экспериментальная часть}

Материалы для эксперилента. Силикат натрия $\mathrm{Na}_{2} \mathrm{SiO}_{3}$ (марки «ч») производства фирмы «Sinopharm Chemical Reagent Co., Ltd.», коммерчески доступен. Поверхностно-активное вещество (ПАВ) представляет собой неионогенное ПАВ DWS производства фирмы «Dalian Davis Technology Co., Ltd.», эффективное содержание ПАВ в растворе $50 \%$. Технологическая вода для проведения опытов является нагнетательной пластовой водой участка «Ү» нефтяного месторождения Туха, массовые концентрации ионов $\left(\mathrm{K}^{+}+\mathrm{Na}^{+}\right), \mathrm{Ca}^{2+}$, $\mathrm{Mg}^{2+}, \mathrm{Cl}^{-}, \mathrm{SO}_{4}{ }^{2-}, \mathrm{CO}_{3}{ }^{2-}$ и $\mathrm{HCO}_{3}{ }^{-}$составляют 51,433; 6,$915 ; 0,393 ; 92,524 ; 0,129$ и 0,059 г/л соответственно. Общая степень минерализации составляет 151,453 г/л. В связи с тем, что в нагнетательной воде содержится большое количество ионов кальция и магния, чтобы уменьшить избыточное содер- жание ионов кальция и магния в пластовой воде, определенное расчетное количество $\mathrm{NaOH}$ и $\mathrm{Na}_{2} \mathrm{CO}_{3}$ добавляли к нагнетательной воде, образующийся осадок $\mathrm{CaCO}_{3}$ и $\mathrm{Mg}(\mathrm{OH})_{2}$ после фильтрования удаляли и таким способом получали частично «смягченную» воду. Нефть, использованная в экспериментах, представляет собой нефть из участка «Y» месторождении Туха, вязкость составляет 6 мПа с при $55^{\circ} \mathrm{C}$.

Керны. В эксперименте использованы искусственные керны, которые были изготовлены из кварцевых песков, цементированных эпоксидной смолой $[20,21]$. Проницаемость искусственных кернов измерялась по пропусканию газа. Керны с различной проницаемостью изготовлены путем использования смесей кварцевого песка с различным размером зерна и содержанием эпоксидной смолы. Геометрический размер керна: высота, ширина и длина составляют 4,5; 4,5 и 30 см соответственно. В экспериментах было исследовано влияние размера оторочек основного агента, количества циклов альтернативного заводнения и ПАВ на увеличение добычи и уменьшение обводненности из неоднородных кернов. Структура неоднородного керна представлена на рис. 1. Керн состоит из трех слоев: с высокой, средней и низкой проницаемостью. Проницаемость слоев составляла $800 \cdot 10^{-3}$, $200 \cdot 10^{-3}$ и $50 \cdot 10^{-3} \mathrm{MKM}^{2}$ соответственно. В экспериментах по исследованию влияния скорости заводнения основного агента на увеличение добычи и уменьшение обводненности использованы однородные керны с разной проницаемостью.

Annаратура. Вязкость исследуемых образцов была определена с использованием вискозиметра Брукфилда DV-II. Эксперименты исследования влияния размера оторочек главного агента, количества циклов альтернативного заводнения и ПАВ на эффективность вытеснения нефти были проведены на фильтрационной установке, которая представлена на рис. 2, a. Эксперименты исследования влияния скорости закачки главного агента на эффективность вытеснения нефти были проведены на фильтрационной установке, которая представлена на рис. 2 , б. Экспериментальная установка состояла из наcoca, датчика давления, промежуточного контейнера и других деталей. За исключением насоса, остальные детали были помещены в термостат с температурой $55^{\circ} \mathrm{C}$. Оборудование для подготовки растворов включало магнитную мешалку НЈ-6, электронные весы, стакан, пробирку, измерительный цилиндр, воронку и термостат HW-IIIA.

План эксперилента. (1) При пластовой температуре закачивают нефть в керн и определяют нефтенасыщенность керна.

(2) Закачивают в керн воду до обводненности $98 \%$ и определяют коэффициент извлечения нефти (КИН) в процессе заводнения.

(3) Альтернативное заводнение основного агента, разделительной жидкости и нагнетательной воды по плану эксперимента (табл. 1). Основной агент - раствор силиката натрия; разделительная 


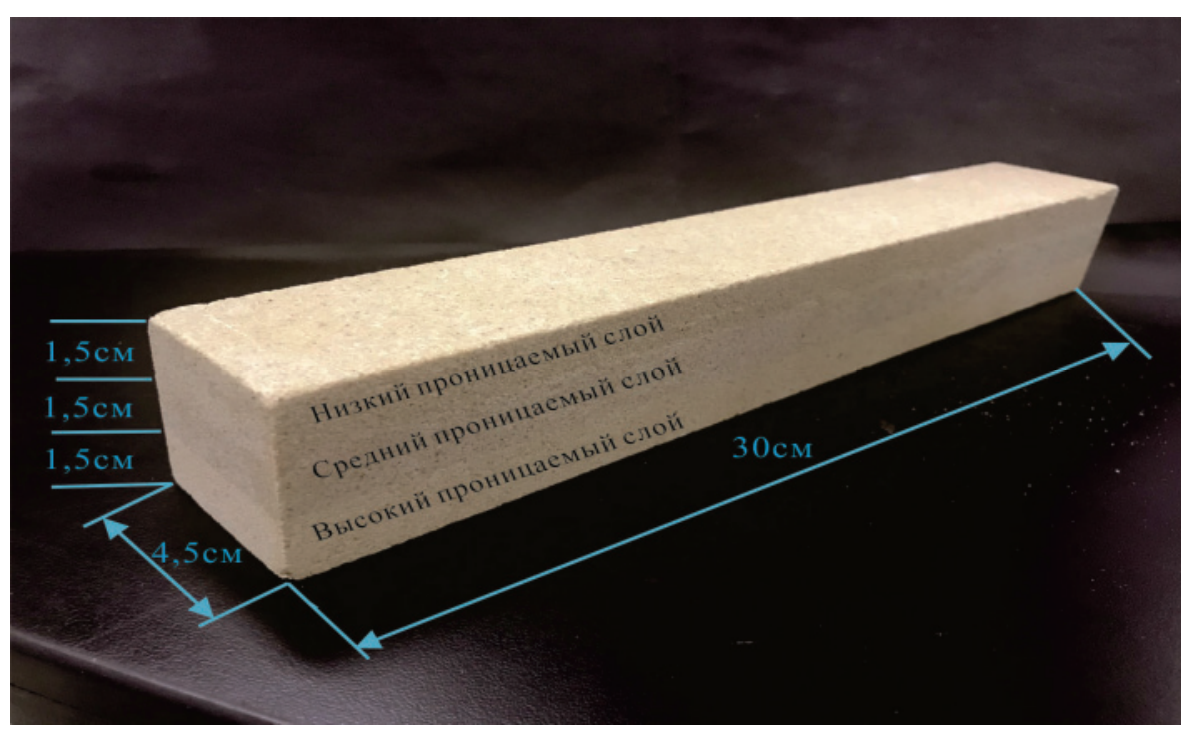

Puс.1. Структура искусственного керна

Fig. 1. Structure of the artificial core
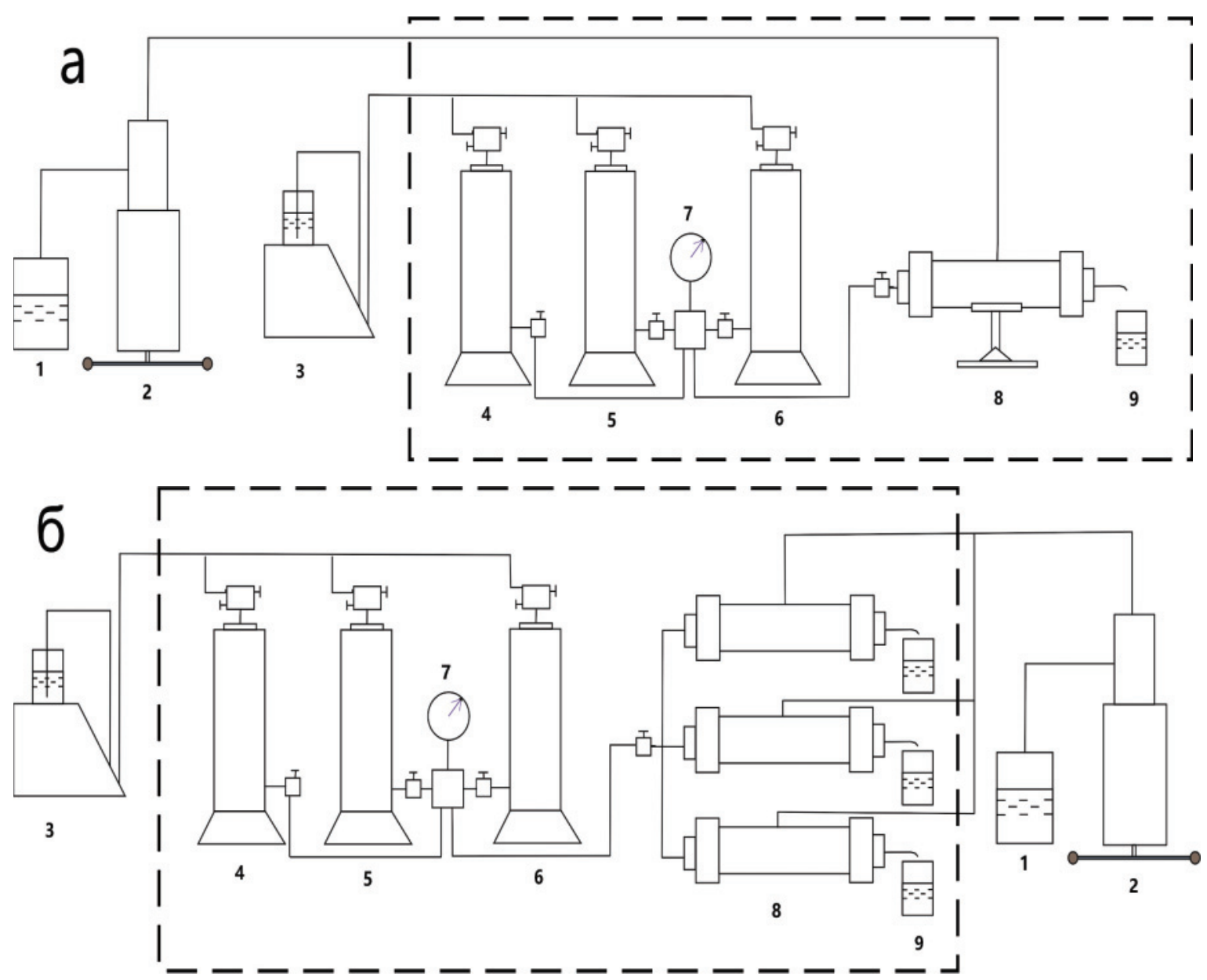

Рис. 2. Приниипильная схема эксперимента: 1 - мерный стакан, 2- ручной насос, 3- поршневой насос, 4- контейнер с нагнетательной водой, 5- контейнер с главным агентом, 6 - контейнер с разделительной жидкостью, 7 - датчик, 8- кернодержатель, 9 мерник

Fig. 2. Schematic diagram of the experiment: 1 is the beaker; 2 is the manual pump; 3 is the plunger pump; 4 is the container with water; 5 is the container with main agent; 6 is the container with separation liquid; 7 is plunger sensor; 8 is the core holder; 9 is the collector 
жидкость - смягченная вода. Объем закачки основного агента и нагнетательной воды одинаковый.

(4) Последующее заводнение до обводненности 98 \% и определение окончательного КИН.

Таблица 1. План экспериментов

Table 1. Experimental plan

\begin{tabular}{|c|c|c|c|c|c|}
\hline 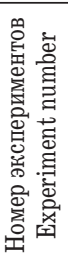 & 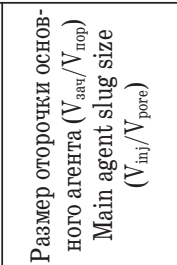 & 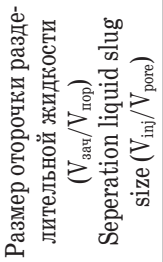 & 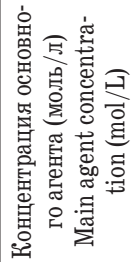 & 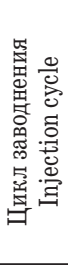 & 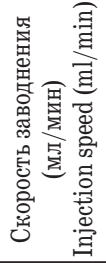 \\
\hline \multicolumn{6}{|c|}{$\begin{array}{c}\text { Влияние размера оторочек основного агента } \\
\text { Influence of the slug size of the main agent }\end{array}$} \\
\hline $1-1$ & 0,04 & \begin{tabular}{|l|}
0,01 \\
\end{tabular} & 0,03 & 6 & 0,03 \\
\hline $1-2$ & 0,06 & 0,015 & 0,03 & 6 & 0,03 \\
\hline $1-3$ & 0,08 & 0,02 & 0,03 & 6 & 0,03 \\
\hline $1-4$ & 0,1 & 0,025 & 0,03 & 6 & 0,03 \\
\hline \multicolumn{6}{|c|}{$\begin{array}{l}\text { Влияние количества циклов заводнения основного агента } \\
\text { Influence of the number of injection cycle of the main agent }\end{array}$} \\
\hline $2-1$ & 0,06 & 0,02 & 0,03 & 4 & 0,03 \\
\hline $2-2$ & 0,06 & 0,02 & 0,03 & 5 & 0,03 \\
\hline $2-3$ & 0,06 & 0,02 & 0,03 & 6 & 0,03 \\
\hline $2-4$ & 0,06 & 0,02 & 0,03 & 7 & 0,03 \\
\hline $2-5$ & 0,06 & 0,02 & 0,03 & 8 & 0,03 \\
\hline \multicolumn{6}{|c|}{ Влияние ПАВ/Influence of surfactant } \\
\hline $3-1$ & 0,06 & \begin{tabular}{|l|}
0,02 \\
\end{tabular} & 0,03 & 6 & 0,03 \\
\hline $3-2$ & $0,06+0,05$ ПАВ & 0,02 & 0,03 & 6 & 0,03 \\
\hline \multicolumn{6}{|c|}{$\begin{array}{l}\text { Влияние скорости заводнения основного агента } \\
\text { Influence of injection speed of the main agent }\end{array}$} \\
\hline $4-1$ & 0,06 & 0,02 & 0,03 & 6 & 0,09 \\
\hline $4-2$ & 0,06 & 0,02 & 0,045 & 6 & 0,06 \\
\hline $4-3$ & 0,06 & 0,02 & 0,09 & 6 & 0,03 \\
\hline
\end{tabular}

\section{Результаты и их обсуждение}

Исследования влияния размера оторочек основного агента на увеличение добычи и уменьшение обводненности проведены по плану эксперимента (табл. 1), результаты представлены в табл. 2. Соотношения между давлением закачки, обводненностью, КИН и $\mathrm{V}_{\text {зач }} / \mathrm{V}_{\text {пор }}$ во время экспериментов показаны на рис. 3. $\left(\mathrm{V}_{\text {зач }}\right.$ - объем закачки жидкости в керн, $\mathrm{V}_{\text {пор }}$ - объем пор керна.)

Из табл. 2 видно, что с увеличением размера оторочек основного агента коэффициент извлечения нефти сначала увеличивается, а затем уменьшается. Когда размер оторочек основного агента изменяется от 0,06 до $0,08 \mathrm{~V}_{\text {зач }} / \mathrm{V}_{\text {пор }}$, образованный осадок в результате реакции не только эффективно блокирует слой с высокой проницаемостью, но также имеет низкую степень неблагоприятного воздействия на слой со средней и низкой проницаемостью и за счет этого увеличивается коэффициент охвата пласта и КИН.

Из рис. 3 видно, что по мере того, как увеличивается размер оторочек основного агента, давление закачки повышается, это указывает на то, что перепад давления и величина абсорбции жидкости в слоях со средней и низкой проницаемостью увеличиваются. Однако это приводит к увеличению начального давления и уменьшению перепада давления в средне-низкопроницаемых слоях, вызванного абсорбцией основного агента и образованием осадков в средне- и низкопроницаемых слоях. Когда размер оторочек основного агента достигает $0,1 \mathrm{~V}_{\text {зач}} / \mathrm{V}_{\text {пор }}$, уменьшается перепад давления абсорбции жидкости, вызванный образованием осад-

Таблица 2. Результаты влияния размера оторочек основного агента на увеличение добычи и уменьшение обводненности

Table 2. $\quad$ Results the influence of the slug size of the main agent on increase in production and water cut reduce

\begin{tabular}{|c|c|c|c|c|c|c|}
\hline \multirow{2}{*}{$\begin{array}{l}\text { Номер экспериментов } \\
\text { Experiment number }\end{array}$} & \multirow{2}{*}{$\begin{array}{l}\text { Параметры } \\
\text { Parameters }\end{array}$} & \multirow{2}{*}{$\begin{array}{c}\text { Размер оторочек глав- } \\
\text { ного агента }\left(\mathrm{V}_{\text {зач }} / \mathrm{V}_{\text {пор }}\right) \\
\text { Main agent slug size } \\
\left(\mathrm{V}_{\text {inj }} / \mathrm{V}_{\text {pore }}\right)\end{array}$} & \multirow[b]{2}{*}{$\begin{array}{c}\text { Нефтенасыщенность } \\
\text { Oil saturation (\%) }\end{array}$} & \multicolumn{3}{|c|}{ КИН (\%) Oil recovery ratio (\%) } \\
\hline & & & & $\begin{array}{c}\text { Заводение } \\
\text { Waterflooding }\end{array}$ & $\begin{array}{l}\text { Последующее заводнение } \\
\text { Subcuquent waterflooding }\end{array}$ & $\begin{array}{l}\text { Прирост КИН } \\
\text { Increase of oil } \\
\text { recovery ratio }\end{array}$ \\
\hline $1-1$ & & 0,04 & 66,96 & 38,57 & 45,86 & 7,29 \\
\hline $1-2$ & & 0,06 & 66,67 & 39,42 & 50,47 & 11,05 \\
\hline $1-3$ & & 0,08 & 65,58 & 39,13 & 49,87 & 10,73 \\
\hline $1-4$ & & 0,1 & 65,80 & 38,62 & 48,20 & 9,58 \\
\hline
\end{tabular}

(a)

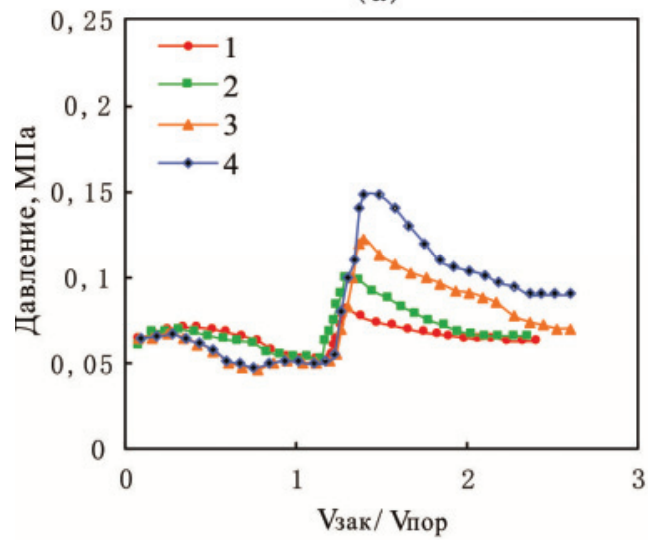

(б)

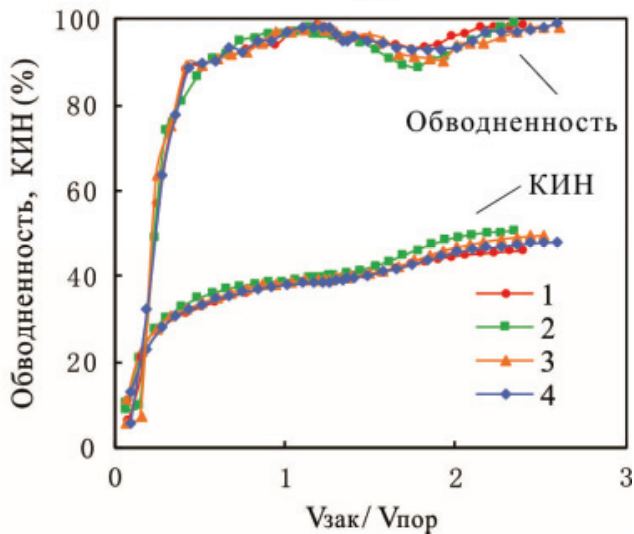

Pис. 3. Зависимость давления (а) и обводненность, КИН (б) от соотношения $V_{\text {зач }} / V_{\text {пор }}: 1-0,04 ; 2-0,06 ; 3-0,08 ; 4-0,1$

Fig. 3. Dependence of pressure (a) and water cut, oil recovery factor (б) on $V_{\text {inj }} / V_{\text {pore }}$ ratio: $1-0,04 ; 2-0,06 ; 3-0,08 ; 4-0,1$ 
Таблица 3. Результаты влияния количества ииклов заводнения основного агента на увеличение добычи и уменьшение обводненности Table 3. Results of the influence of the number of injection cycle of the main agent on increase in production and water cut reduce

\begin{tabular}{|c|c|c|c|c|c|c|}
\hline \multirow[b]{2}{*}{$\begin{array}{l}\text { Номер экспериментов } \\
\text { Experiment number }\end{array}$} & \multirow{2}{*}{$\begin{array}{r}\text { Параметры } \\
\text { Parameters } \\
\end{array}$} & \multirow{2}{*}{\begin{tabular}{|c} 
Цикл \\
заводнения \\
Injection \\
cycle
\end{tabular}} & \multirow[b]{2}{*}{$\begin{array}{c}\text { Нефтенасыщенность } \\
\text { Oil saturation (\%) }\end{array}$} & \multicolumn{3}{|c|}{ КИН $(\%) /$ Oil recovery ratio $(\%)$} \\
\hline & & & & $\begin{array}{c}\text { Заводнение } \\
\text { Waterflooding }\end{array}$ & $\begin{array}{l}\text { Последующее заводнение } \\
\text { Subcuquent waterflooding }\end{array}$ & $\begin{array}{l}\text { Прирост КИН } \\
\text { Increase of oil } \\
\text { recovery ratio }\end{array}$ \\
\hline $2-1$ & & 4 & 65,52 & 39,34 & 46,89 & 7,55 \\
\hline $2-2$ & & 5 & 65,37 & 38,74 & 47,95 & 9,21 \\
\hline $2-3$ & & 6 & 66,67 & 39,42 & 50,47 & 11,05 \\
\hline $2-4$ & & 7 & 65,24 & 39,21 & 46,94 & 7,74 \\
\hline $2-5$ & & 8 & 65,41 & 39,06 & 45,16 & 6,09 \\
\hline
\end{tabular}

(a)

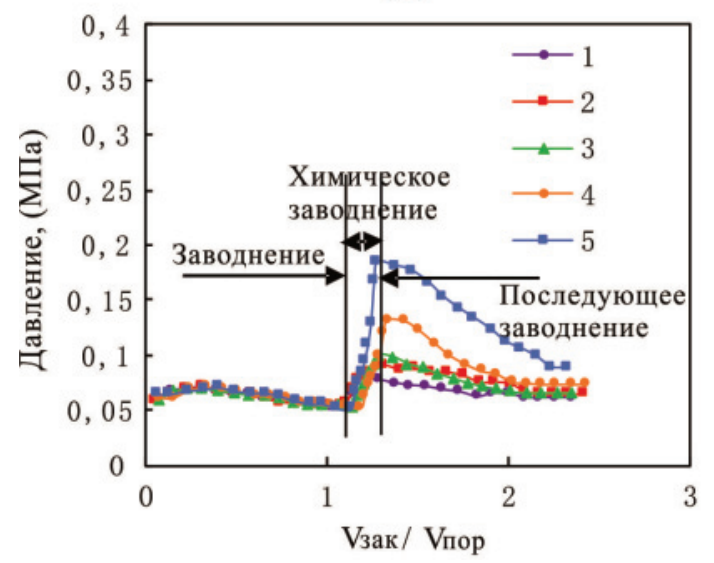

(б)

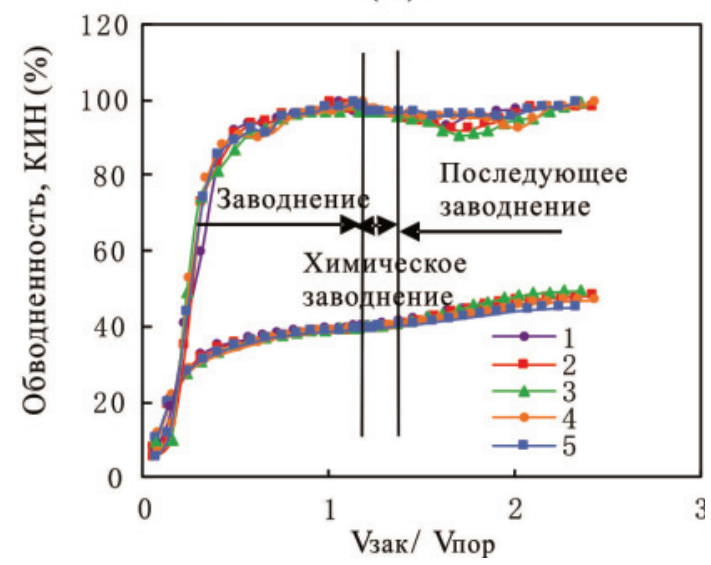

Pис. 4. Зависимости давления (а) и обводненности, КИН (б) от соотношения пять, 3 - шесть, 4 - семь, 5 - восемь

Fig. 4. Dependence of pressure (a) and water cut, oil recovery factor (б) on the ratio $V_{\text {inj }} / V_{\text {pore. }}$ Number of injection cycles: 1 - four, 2 - five, 3 six, 4 - seven, 5 - eight

ков в средне- и низкопроницаемых слоях, и коэффициент охвата пласта и КИН увеличиваются. Когда размер оторочек основного агента изменяется от 0,06 до $0,08 \mathrm{~V}_{\text {зач }} / \mathrm{V}_{\text {пор }}$, средне- и низкопроницаемые слои пласта имеют более высокую степень использования, обводненность значительно уменьшается и КИН увеличивается.

Исследования влияния количества циклов заводнения основного агента на увеличение добычи и уменьшение обводненности проведены по плану эксперимента (табл. 1), результаты представлены в табл. 3. Соотношение между давлением закачки, обводненностью, КИН и $\mathrm{V}_{\text {зач}} / \mathrm{V}_{\text {пор }}$ во время экспериментов показаны на рис. 4.

Из табл. 3 видно, что с увеличением количества циклов альтернативного заводнения КИН сначала увеличивается, а затем уменьшается. Когда цикл альтернативного заводнения равен шести, образованный в результате реакции осадок не только эффективно блокирует слой с высокой проницаемостью, но также имеет низкую степень неблагоприятного воздействия на слой со средней и низкой проницаемостью и коэффициент охвата пласта и КИН повышаются. На рис. 4 видно, что с увеличением цикла альтернативного заводнения давление закачки постепенно повышается. С одной стороны, повышение давления закачки увеличивает перепад давления абсорбции жидкости в слоях со сред- ней и низкой проницаемостью, а с другой стороны приводит к увеличению начального давления и уменьшению перепада давления абсорбции жидкости, в связи с абсорбцией главного агента и образованием осадков в слоях со средней и низкой проницаемостью. Когда цикл альтернативного заводнения превышает 6 , давление закачки увеличивается в связи с абсорбцией главного агента и образованием осадков в слоях со средней и низкой проницаемостью, что приводит к значительному повышению начального давления и уменьшению перепада давления абсорбции жидкости и к уменьшению объема охвата пласта и КИН. Когда цикл альтернативного заводнения составляет $5-6$, слои со средней и низкой проницаемостью имеют более высокую степень использования, обводненность значительно уменьшается и КИН увеличивается.

Влияние поверхностного активного вещества (ПАВ) на увеличение добычи и уменьшение обводненности проведены по плану эксперимента (табл. 1), результаты представлены в табл. 4. Концентрация ПАВ равна 0,3 \% . Соотношения между давлением закачки, обводненностью, КИН и $\mathrm{V}_{\text {зач }} / \mathrm{V}_{\text {пор }}$ показаны на рис. 5.

Из табл. 4 видно, что при одинаковых условиях применения основного агента КИН сочетания силиката и ПАВ больше, чем одиночного силиката. Это показывает, что сочетание силиката и ПАВ мо- 
Таблица 4. Результаты влияния ПАВ на увеличение добычи и уменьшение обводненности

Table 4. $\quad$ Results of the influence of surfactant on increase in production and water cut reduce

\begin{tabular}{|c|c|c|c|c|c|c|}
\hline \multirow[b]{2}{*}{$\begin{array}{l}\text { Номер экспериментов } \\
\text { Experiment number }\end{array}$} & \multirow{2}{*}{$\begin{array}{l}\text { Параметры } \\
\text { Parameters }\end{array}$} & \multirow{2}{*}{$\begin{array}{c}\text { Вид вытесняющего } \\
\text { агента } \\
\text { Displacing agent type }\end{array}$} & \multirow{2}{*}{$\begin{array}{c}\text { Нефтенасы- } \\
\text { щенность } \\
\text { Oil saturation } \\
(\%)\end{array}$} & \multicolumn{3}{|c|}{ КИН $(\%) /$ Oil recovery ratio $(\%)$} \\
\hline & & & & $\begin{array}{c}\text { Заводнение } \\
\text { Waterflooding }\end{array}$ & $\begin{array}{l}\text { Последующее заводнение } \\
\text { Subcuquent waterflooding }\end{array}$ & $\begin{array}{l}\text { Прирост КИН } \\
\text { Increase of oil } \\
\text { recovery ratio }\end{array}$ \\
\hline $3-1$ & & Главный агент & 66,67 & 39,42 & 50,47 & 11,05 \\
\hline $3-2$ & & Главный агент +ПАВ & 66,34 & 39,31 & 52,48 & 13,16 \\
\hline
\end{tabular}

(a)

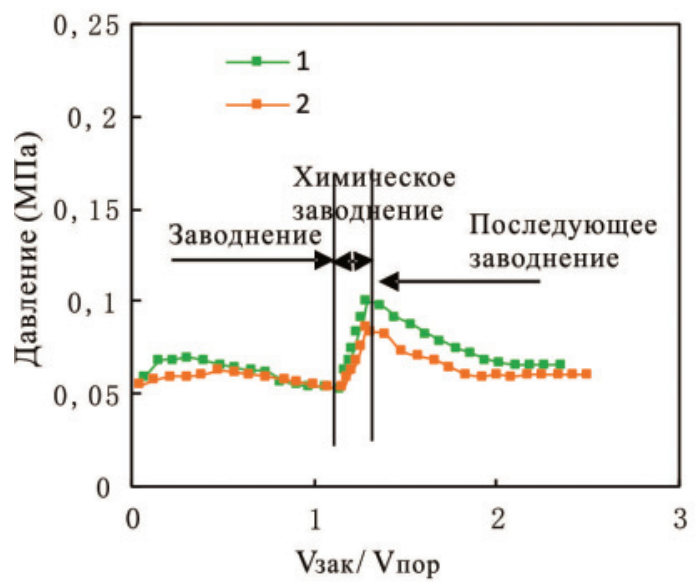

(б)

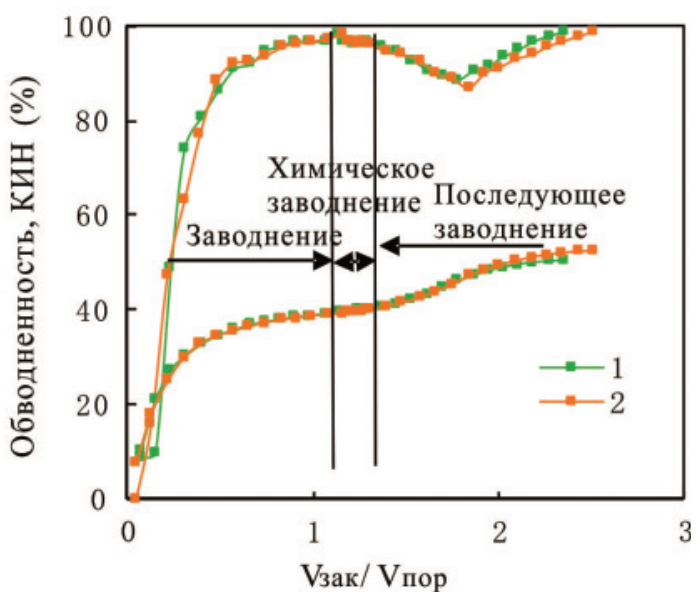

Pис. 5. Зависимости давления (а) и обводненности, КИН (б) от соотношения $V_{\text {зач }} / V_{\text {пор. }} 1-$ главный агент, $2-$ главный агент + ПАВ

Fig. 5. Dependence of pressure (a) and water cut, oil recovery factor (б) on the ratio $V_{\text {inj }} / V_{\text {pore. }} 1$ is the main agent, 2 is the main agent + surfactant

Таблица 5. Результаты влияния скорости заводнения основного агента на увеличение добычи и уменьшение обводненности Table 5. Results of the effect of the injection speed of the main agent on increase in production and decrease in water cut

\begin{tabular}{|c|c|c|c|c|c|}
\hline \multirow[b]{2}{*}{$\begin{array}{l}\text { Номер экспериментов } \\
\text { Experiment number }\end{array}$} & \multirow{2}{*}{$\begin{array}{c}\text { Скорость заводнения } \\
\text { основного агента (мл/мин) } \\
\text { Injection speed of the main } \\
\text { agent }(\mathrm{ml} / \mathrm{min})\end{array}$} & \multirow{2}{*}{$\begin{array}{c}\text { Нефтенасы- } \\
\text { щенность } \\
\text { Oil saturation } \\
\text { (\%) }\end{array}$} & \multicolumn{3}{|c|}{ КИН (\%)/Oil recovery ratio (\%) } \\
\hline & & & $\begin{array}{c}\text { Заводнение } \\
\text { Waterflooding }\end{array}$ & $\begin{array}{l}\text { Последующее заводнение } \\
\text { Subcuquent waterflooding }\end{array}$ & $\begin{array}{l}\text { Прирост КИН } \\
\text { Increase of oil } \\
\text { recovery ratio }\end{array}$ \\
\hline $4-1$ & 0,09 & 64,05 & 38,64 & 47,47 & 8,83 \\
\hline $4-2$ & 0,06 & 63,81 & 39,23 & 48,79 & 9,54 \\
\hline $4-3$ & 0,03 & 64,61 & 39,31 & 49,87 & 10,56 \\
\hline
\end{tabular}

(a)

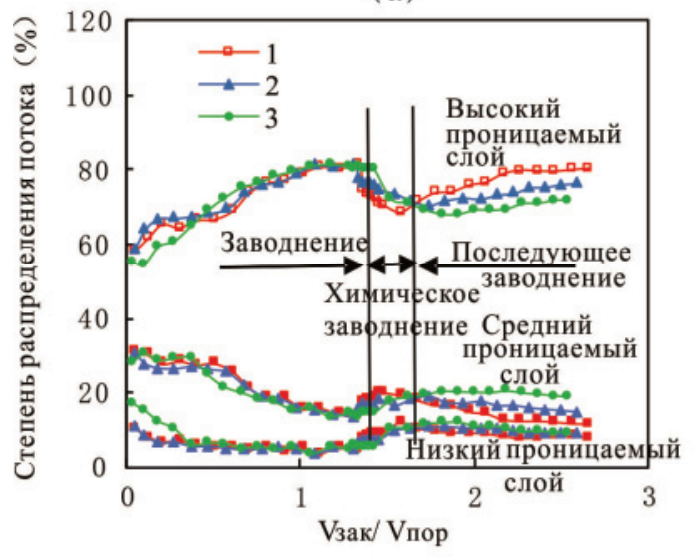

(б)

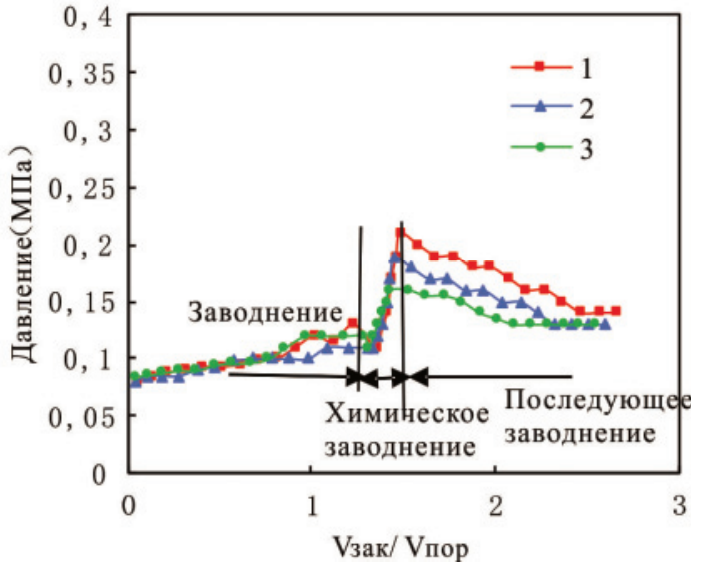

Puс. 6. Зависимость степени распределения потока (а) и давления (б) от $V_{3 а к} / V_{\text {пор: }} 1-0,9$ мл/мин, 2-0,6 мл/мин, 3 -0,3 мл/мин Fig. 6. Dependence of the degree of flow (a) and pressure distribution (б) on $V_{\text {inj }} / V_{\text {pore }}: 1-0,9 \mathrm{~mL} / \mathrm{min}, 2-0,6 \mathrm{~mL} / \mathrm{min}, 3-0,3 \mathrm{~mL} / \mathrm{min}$. 
жет достигать цели расширения объема охвата и повышения эффективности вытеснения нефти и увеличивает КИН.

Из рис. 5 видно, что в процессе заводнения с увеличением $\mathrm{V}_{\text {зач}} / \mathrm{V}_{\text {пор }}$ давление закачки уменьшается, обводненность и КИН увеличиваются. На стадии контроля профиля, по сравнению с одиночным силикатом натрия, давление закачки и тенденция изменения сочетания силиката и ПАВ практически не изменяется, это указывает на то, что перепад давления абсорбции и степень поглощения жидкости в слоях со средней и низкой проницаемостью не увеличиваются, в связи с тем, что раствор ПАВ улучшает эффективность вытеснения нефти и увеличивает КИН.

Исследования влияния скорости заводнения основного агента на увеличение добычи и уменьшение обводненности проведены по плану эксперимента (табл. 1), результаты представлены в табл. 5 . Соотношение между давлением закачки, обводненностью, КИН и $\mathrm{V}_{\text {зач }} / \mathrm{V}_{\text {пор }}$ показаны на рис. 6 .

Из табл. 5 и рис. 6 видно, что при снижении скорости закачки основного агента прирост КИН увеличивается. Когда скорость закачки основного агента уменьшается, давление закачки снижается. Из-за высокого давления закачки в слои со средней и низкой проницаемостью и низкого давления закачки в слои с высокой проницаемостью снижение давления закачки позволяет большему количеству химических агентов проникать в слои с высокой проницаемостью, в слое с высокой проницаемостью образуется больше осадков и повышается прочность закупорки. С уменьшением поглощения основного агента в слоях средней и низкой проницаемости количество образующегося осадка уменьшается, поэтому влияние на способность поглощения жидкости слоев средней и низкой проницаемости мало. В процессе последующего заводнения

\section{СПИСОК ЛИТЕРАТУРЫ}

1. Sheng J.J., Leonhardt B., Nasser A. Status of polymer-flooding technology // Journal of Canadian petroleum technology. 2015. - V. 54. - № 2. - P. 116-125.

2. Raffa P., Broekhuis A.A., Pocchioni F. Polymeric surfactants for enhanced oil recovery: a review // Journal of Petroleum Science and Engineering. - 2016. - V. 145. - № 9. - P. 723-733.

3. Исследование фильтрационных и реологических свойств полимерного геля для повышения нефтеотдачи пластов / Нажису, В.И. Ерофеев, Ц. Лу, В. Ван // Известия Томского политехнического университета. Инжиниринг георесурсов. - 2019. T. 330. - № 4. - C. 147-157.

4. Druetta P., Picchioni F. Polymer and nanoparticles flooding as a new method for Enhanced Oil Recovery // Journal of Petroleum Science and Engineering. - 2019. - V. 177. - № 6. - P. 479-495.

5. Research progress of temperature resistant and salt-resistant polymers for oil-displacing agent / Y. Wang, N. Li, Z. Zhang, J. Zhou // Fine and Specially Chemicals. - 2010. - V. 18. № 10. - P. 35-38.

6. Wang J., Dong M. Optimum effective viscosity of polymer solution for improving heavy oil recovery // Journal of Petroleum Science and Engineering. - 2009. - V. 67. - № 8. - P. 155-158. эффект управления потоком жидкости улучшается, объем охвата слоев со средней и низкой проницаемостью увеличивается и повышается КИН.

\section{Заключение}

1. С увеличением размера оторочек основного агента и количества циклов альтернативного заводнения прирост давления закачки повышается, что увеличивает объем поглощения жидкости слоев средней и низкой проницаемости, а также приводит к образованию осадков в слоях средней и низкой проницаемости, к повышению пускового давления и уменьшению перепада давления поглощения жидкости в слоях со средней и низкой проницаемостью. Когда размер оторочек основного агента изменяется от 0,06 до 0,08 $\mathrm{V}_{\text {зак }} / \mathrm{V}_{\text {пор }}$ и цикл альтернативного заводнения составляет 5-6, степень использования слоев со средней и низкой проницаемостью является более высокой, обводненность пласта значительно уменьшается и КИН увеличивается.

2. По сравнению с одиночным силикатным заводнением сочетание одновременного введения силиката натрия и ПАВ приводит к значительному увеличению объема охвата, повышению әффективности вытеснения нефти и росту КИН.

3. Снижение скорости закачки основного агента приводит к уменьшению способности поглощения жидкости в слоях с низкой и средней проницаемостью, улучшению способности управления потоком и увеличению КИН.

Работа выполнена при поддержке научно-исследовательского и технического проекта Китайской национальной нефтегазовой корпорации, "Исследование и применение ключевых технологий для разведки и разработки месторождений Синьизян и Туха» (2017Е-0407); Китайского национального фонда для обучения за рубежом.

7. Algharaib M., Alajmi A., Gharbi R. Improving polymer flood performance in high salinity reservoirs // Journal of Petroleum Science and Engineering. - 2014. - V. 115. - № 3. - P. 17-23.

8. Matching between the diameter of the aggregates of hydrophobically associating polymers and reservoir pore-throat size during polymer flooding in an offshore oilfield / K. Xie, B. Cao, X. Lu, W. Jiang, Y. Zhang, Q. Li, K. Song, J. Liu, W. Wang, J. Lv, R. Na // Journal of Petroleum Science and Engineering. 2019. - V. 177. - № 6. - P 558-569.

9. Analysis of reservoir applicability of hydrophobically associating polymer / K. Xie, X. Lu, Q. Li, W. Jiang, Q. Yu // SPE Journal. - 2016. - V. 21. - № 1. - P. 1-9.

10. Research and advances of silicate plugging agent in domestic and overseas oilfields / J. Zhao, W. Xiang, J. Zhang, R. Xin, C. Dai // Oilfield Chemistry. - 2015. - V. 32. - № 1. - P. 146-150.

11. Влияние минерализации пластовых вод на физико-химические и фильтрационные характеристики полимерных растворов и гелей для повышения нефтеотдачи пластов / Нажису, В.И. Ерофеев, С. Лу, Ц. Лу, В. Ван, Л. Чжан // Известия Томского политехнического университета. Инжиниринг георесурсов. - 2019. - Т. 330. - № 3. - С. 136-145.

12. Experimental study on gelling property and plugging effect of inorganic gel system (OMGL) / L. Niu, X. Lu, C. Xiong, X. Tang, 
X. Wu, X. Jia., S. Zhang // Petroleum exploration and development. -2013 . - V. 40, - № 6. - P. 728-732.

13. Mechanism and gelling effects of linked polymer solution in the core / J. Liu, X. Lu, J. Liu, S. Hu, B. Xue // Petroleum exploration and development. - 2013. - V. 40. - № 4. - P. 474-480.

14. Dong M., Ma S., Liu Q. Enhanced heavy oil recovery through interfacial instability: a study of chemical flooding for brintnell heavy oil // Fuel. - 2009. - V. 88. - № 6. - P. 1049-1056.

15. Lieu T.P., Hatzignatiou D.G. Rheological evaluation of a sodium silicate gel system for water management in mature, naturallyfractured oilfields // Journal of Petroleum Science and Engineering. - 2016. - V. 138. - № 2. - P. 218-233.

16. Laboratory testing of environmentally friendly sodium silicate systems for water management through conformance control / D.G. Hatzignatiou, R. Askarinezhad, N.H. Giske, A. Stavland // SPE Production \& Operations. - 2016. - V. 31. - № 4. P. $337-350$.

17. Дурягин В.Н., Стрижнев К.В. Разработка неорганического водоизоляционного состава на основе силиката натрия для низкопроницаемых неоднородных коллекторов // Нефтегазовое де- ло: электронный научный журнал. - 2014. - № 1. - С. 14-29. URL: http://dx.doi.org/10.17122/ogbus-2014-1-14-29 (дата обращения 15.12.2018).

18. Effect of profile-control oil-displacement agent on increasing oil recovery and its mechanism / W. Cao, K. Xie, X. Lu, Y. Liu, Y. Zhang // FUEL. - 2019. - V. 237. - № 1. - P. 1151-1160.

19. Jiang W., Zhang J., Tang X. Compatibility of clew dimension of flooding polymer and rock pore throat in bohai oilfield // Oilfield Chemistry. - 2012. - V. 29. - № 4. - P. 446-451.

20. Lu X., Gao Z., Yan W. Experimental study of factors influencing permeability of artificial core // Petroleum Geology \& Oilfield Development in Daqing. - 1994. - V. 13. - № 4. - P. 53-55.

21. Analysis of dynamic imbibition effect of surfactant in micro cracks in reservoir with high temperature and low permeability / K. Xie, X. Lu, H. Pan, D. Han, G. Hu, J. Zhang, B. Zhang, B. Cao // SPE Production \& Operations. - 2018. - V. 33. - № 3. P. 596-606.

\section{Информация об авторах}

Нажису, аспирант отделения нефтегазового дела Школы природных ресурсов Национального исследовательского Томского политехнического университета.

Eрофеев В.И., доктор технических наук, профессор отделения нефтегазового дела Школы природных ресурсов Национального исследовательского Томского политехнического университета.

Лу Сянго, доктор технических наук, профессор Института нефтегазового дела Северо-Восточного нефтяного университета.

Тянь Чжунъюань, магистр ключевой лаборатории Министерства образования по увеличению нефтеотдачи пластов Института нефтегазового дела Северо-Восточного нефтяного университета.

Чжан Лидонг, инженер Научно-исследовательского инженерно-технологического института нефтяного месторождения Тух. 
UDC 622.276

\title{
OPTIMIZATION OF PARAMETERS OF INORGANIC PROFILE CONTROL AGENT ON THE BASIS OF SODIUM SILICATE FOR EFFECTIVE OIL DISPLACEMENT FROM HIGH SALINITY RESERVOIR
}

Narisu',

Narisu33@126.com

Vladimir I. Erofeev',

erofeevvi@mail.ru

Lu Xiangguo ${ }^{2}$,

877459272@qq.com

Tian Zhongyuan ${ }^{2}$, jinjigema@126.com

\author{
Zhang Lidong ${ }^{3}$, \\ 1052287742@qq.com \\ ${ }^{1}$ National Research Tomsk Polytechnic University, \\ 30, Lenin Avenue, Tomsk, 634050, Russia. \\ ${ }^{2}$ Northeast Petroleum University, \\ 199, Razvitiya street, Daqing, 163000, China. \\ ${ }^{3}$ Tuha Oilfield Engineering and Technology Research Institute, \\ 67, Osvobozhdeniya street, Shanshan, 838202, China.
}

The relevance. Oil field Tuha is a medium and low permeability reservoir, with high salinity water. Currently, the water cut of the main productive layer in the "Y» section of the Tuha oil field is more than $93 \%$. Existing polymers and salt-resistant polymers cannot be well dissolved and distributed in layer water, and also have poor retention in the reservoir and profile control ability, hence, it is difficult to achieve a good technical and economic effect. So, it is important to investigate the method of profile management for effective oil displacement from reservoirs with high mineralization.

The main aim of the research is to study oil displacement efficiency and optimization of parameters of inorganic profile agent based on sodium silicate for enhanced oil recovery.

Methods. Viscosity of the studied samples was determined on a Brookfield DV-II viscometer; the experiments investigating the effect of the slug size of main agent, the number of cycles of alternative waterflooding, the injection speed of main agent and the injection of surfactant on the oil displacement efficiency were carried out on filtration unit.

Results. In order to satisfy the demand of enhanced oil recovery at this oil field, the experimental studies were carried out to optimize parameters and increase the efficiency of oil displacement of the inorganic silicate profile control agent based on the geological characteristics of the reservoir and fluid properties of the "Y $Y$ » sections. The results show that when the size of the slug of the main agent is from 0,06 to 0,08 $V_{\text {ini }} / V_{\text {pore }}$ and the cycle of alternative flooding is 5-6, the degree of using the layers with medium and low permeability is higher, the water cut decreases and oil recovery increases significantly. Compared to single silicate flooding, the combination of silicate and surfactants can achieve the goal of expanding the scope of coverage and improving the efficiency of oil displacement, and increases the oil recovery factor.

\section{Key words:}

Reservoirs with high mineralization, silicate, optimization, oil recovery coefficient, alternative waterflooding.

The research was supported by the scientific and research project of Chinese national oil and gas corporation «Study and application of key techniques for exploration and development of deposits Xinjiang and Tuha "(2017E-0407); and Chinese national Fund for studying abroad.

\section{REFERENCES}

1. Sheng J.J., Leonhardt B., Nasser A. Status of polymer-flooding technology. Journal of Canadian petroleum technology, 2015, vol. 54, no. 2, pp. 116-125.

2. Raffa P., Broekhuis A.A., Pocchioni F. Polymeric surfactants for enhanced oil recovery: A review. Journal of Petroleum Science and Engineering, 2016, vol. 145, no. 9, pp. 723-733.

3. Narisu, Erofeev V.I., Lv J., Wang W. Study on filtration and rheological properties of polymer gel to improve oil recovery. Bulle- tin of the Tomsk Polytechnic University. Geo Assets Engineering, 2019, vol. 330, no. 3, pp. 147-157. In Rus.

4. Druetta P., Picchioni F. Polymer and nanoparticles flooding as a new method for Enhanced Oil Recovery. Journal of Petroleum Science and Engineering, 2019, vol. 177, no. 6, pp. 479-495.

5. Wang Y., Li N., Zhang Z., Zhou J. Research progress of temperature resistant and salt-resistant polymers for oil-displacing agent. Fine and Specially Chemicals, 2010, vol.18, no. 10, pp. 35-38. 
6. Wang J., Dong M. Optimum effective viscosity of polymer solution for improving heavy oil recovery. Journal of Petroleum Science and Engineering, 2009, vol. 67, no. 8, pp. 155-158.

7. Algharaib M., Alajmi A., Gharbi R. Improving polymer flood performance in high salinity reservoirs. Journal of Petroleum Science and Engineering, 2014, vol. 115, no. 3, pp. 17-23.

8. Xie K., Cao B., Lu X, Jiang W., Zhang Y., Li Q., Song K., Liu J., Wang W., Lv J., Na R. Matching between the diameter of the aggregates of hydrophobically associating polymers and reservoir pore-throat size during polymer flooding in an offshore oilfield. Journal of Petroleum Science and Engineering, 2019, vol. 177, no. 6 , pp. $558-569$.

9. Xie K., Lu X., Li Q., Jiang W., Yu Q. Analysis of reservoir applicability of hydrophobically associating polymer. SPE Journal, 2016, vol. 21, no. 1, pp. 1-9.

10. Zhao J., Xiang W., Zhang J., Xin R., Dai C. Research and advances of silicate plugging agent in domestic and overseas oilfields. Oilfield Chemistry, 2015, vol. 32, no. 1, pp. 146-150.

11. Narisu, Erofeev V.I., Lu X. Lv J., Wang X., Zhang L. The effect of layer water mineralization on physical chemical and filtration characteristics of polymeric solutions and gels for increasing oil recovery. Bulletin of the Tomsk Polytechnic University. Geo Assets Engineering, 2019, vol. 330, no. 4, pp. 136-145. In Rus.

12. Niu L., Lu X., Xiong C., Tang X., Wu X., Jia X., Zhang S. Experimental study on gelling property and plugging effect of inorganic gel system (0MGL). Petroleum exploration and development, 2013, vol. 40, no. 6, pp. 728-732

13. Liu J., Lu X., Liu J., Hu S., Xue B. Mechanism and gelling effects of linked polymer solution in the core. Petroleum exploration and development, 2013, vol. 40, no. 4, pp. 474-480.

14. Dong M., Ma S., Liu Q. Enhanced heavy oil recovery through interfacial instability: a study of chemical flooding for brintnell heavy oil. Fuel, 2009, vol. 88, no. 6, pp. 1049-1056.
15. Lieu T.P., Hatzignatiou D.G. Rheological evaluation of a sodium silicate gel system for water management in mature, naturallyfractured oilfields. Journal of Petroleum Science and Engineering, 2016, vol. 138, no. 2, pp. 218-233.

16. Hatzignatiou D.G., Askarinezhad R., Giske N.H., Stavland A. Laboratory testing of environmentally friendly sodium silicate systems for water management through conformance control. SPE Production \& Operations, 2016, vol. 31, no. 4. pp. 337-350.

17. Duryagin V.N., Strizhnev K.V. Development of sodium silicatebased inorganic water shut-off composition for low-permeability heterogeneous reservoirs. Neftegazovoe delo: elektronny nauchny zhurnal, 2014, no. 1, pp. 14-29. In Rus. Available at: http://dx.doi.org/10.17122/ogbus-2014-1-14-29 (accessed 15 December 2018).

18. Cao W., Xie K., Lu X., Liu Y., Zhang Y. Effect of profile-control oil-displacement agent on increasing oil recovery and its mechanism. Fuel, 2019, vol. 237, no. 1, pp. 1151-1160.

19. Jiang W., Zhang J., Tang X. Compatibility of clew dimension of flooding polymer and rock pore throat in bohai oilfield. Oilfield Chemistry, 2012, vol. 29, no. 4, pp. 446-451.

20. Lu X., Gao Z., Yan W. Experimental study of factors influencing permeability of artificial core. Petroleum Geology \& Oilfield Development in Daqing, 1994, vol. 13, no. 4, pp. 53-55.

21. Xie K., Lu X., Pan H., Han D., Hu G., Zhang J., Zhang B., Cao B. Analysis of dynamic imbibition effect of surfactant in micro cracks in reservoir with high temperature and low permeability. SPE Production \& Operations, 2018, vol. 33, no. 3, pp. 596-606.

Received: 17 December 2018.

\section{Information about the authors}

Narisu, post-graduate student, National Research Tomsk Polytechnic University.

Vladimir I. Erofeev, Dr. Sc., Academician of RANS, professor, National Research Tomsk Polytechnic University.

Lu Xiangguo, Dr. Sc., professor, Northeast Petroleum University.

Tian Zhongyuan, graduate student, Northeast Petroleum University.

Zhang Lidong, engineer, Tuha Oilfield Engineering and Technology Research Institute. 